\title{
Forecasting Daily Returns: A Comparison Of Neural Networks With Parametric Regression Analysis
}

Dimitrios Angelidis, University of Macedonia, Greece

Katerina Lyroudi, (Email: lyroudi@uom.gr),University of Macedonia, Greece

Athanasios Koulakiotis, University of the Aegean, Greece

\begin{abstract}
Since the seminal work of Fama (1965), many researchers have found that the actual distribution of stock returns, for the USA market, is significantly non-normal. Our study is focusing on the examining stock returns predictability for the Hellenic market given some macroeconomic variables. The objective is to use the given information set to reach an optimal way for forecasting. Hence, two basic models for forecasting are examined; a multivariable OLS regression approach and a non-parametric neural network approach and we compare them, based on the minimum forecasted error. Then, the approach that gives the minimum forecasting error is selected. The results indicated that better forecasting approach between the selected two ones is the neural network regression, since it has the smaller mean absolute percent error.
\end{abstract}

\section{INTRODUCTION}<smiles>[LiH]</smiles>

ince the seminal work of Fama (1965), many researchers have found that the actual distribution of stock returns, for the USA market, is significantly non-normal. [Hsu et al (1974), Hagerman (1978), Lau at al. (1990), Kim and Kon (1994)]. Their results indicated that the distribution of stock returns is leptokurtic (higher kurtosis than the normal distribution), skewed either to the left (negative skewness) or to the right (positive skewness) and that the variance of the distribution is not constant over time, as the normal distribution requires and many conventional econometric models as well.

Lo and MacKinlay (1988) claimed that stock prices did not follow random walks and provided evidence that stock returns were to some extent predictable. For the US markets, several studies examined the cross-sectional relationship between stock returns and fundamental variables. The variables earnings, cash flows, book to market ratio and size have been found to have some predictive power regarding stock returns. [Basu (1997), Fama and French (1992) and Lakonishok, Shleifer and Vishny (1994)]. Other studies found that macroeconomic variables have some power to predict stock returns,, such as short-term interest rates, expected inflation, divided yields, yield spreads between long and short term government bonds, lagged stock price to earnings ratios, lagged returns, changes in aggregate production, the risk premium, the slope of the term structure and others. [Fama and Schwert (1977), Chen, Roll and Ross (1986), Campbell (1987) and Fama and French (1988a, b)].

Our study is focusing on the examining stock returns predictability for the Hellenic market given some macroeconomic variables. The objective is to use the given information set to reach an optimal way for forecasting. Hence, two basic models for forecasting are examined; a multivariable OLS regression approach and a non-parametric neural network approach and we compare them, based on the minimum forecasted error. Then, the approach that gives the minimum forecasting error is selected. This study will be also useful for practitioners and financial analysts, since they could rely on the accurate prediction of the stock prices to determine their trading practices. 
In order to achieve our objective, the study is structured as follows: The next section discusses the literature on stock prices predictability. The third section contains a description of the data and the two methodologies. The fourth section discusses the results. The final section presents the summary and concluding remarks.

\section{LITERATURE REVIEW}

In the international literature regarding forecasting of stock market prices there is a variety of models. Coother (1962), Osborne $(1959,1962)$ applied first simple linear autoregressive models. Peters (1989), Hiemstra and Kramer (1995) applied first more sophisticated non-linear dynamic models.

Akgiray (1989) found evidence about the temporal behavior of stock market returns. He applied GARCH $(1,1)$ models (generalized autoregressive conditional heteroskedasticity) and found that time series of daily stock returns exhibit significant levels of second-order dependence, hence they could not be modeled as linear white-noise processes. Also, he found that these models fit the data satisfactorily, since conditional heteroscedastic processes allowed for autocorrelation between the first and second moments of the returns' distribution over time. He recommended future research to focus on general nonlinear models, which would allow for dependence in higher order moments.

Corhay and Tourani (1994) tried to investigate the effectiveness of the GARCH models in analyzing daily stock returns behavior. Specifically they investigated stock price behavior in five European countries, which were smaller and thinner than the American stock markets. The countries were France, Germany, Italy, the Netherlands and the United Kingdom. Their results verified that the daily stock returns were not normally distributed; instead they were leptokurtic and skewed negatively. Moreover, based on the results, conditional heteroskedasticity was a prime feature of daily returns behavior of the above five market indices. The GARCH-t $(1,1)$, in other words a GARCH model with conditional errors that are t-distributed, fits the data best.

Leung, Daouk and Chen (2000) evaluated the efficacy of several models in forecasting the stock prices or returns for the US, the UK and the Japanese markets, for the period 1967-1995. They used linear discriminate analysis, logia, probit and probabilistic neural network on one side (classification models), and exponential smoothing multivariate transfer function, vector auto regression with Kalman filter, and multilagered feed forward neural network on the other side (estimation models). They used macroeconomic variables as the predictors, such as the interest rates, the consumer price index, the industrial production and lagged returns. Their results indicated that the selected classification models had superior forecasting performance than the estimation models.

Basci, Basci and Muradoglu (2003) examined weekly national index returns for 21 world markets (16 emerging and 5 developed stock markets), for the period 1989-1998. The data was obtained from DataStream. The models used were a non-linear time series model and a third order polynomial autoregressive model PAR $(3,1)$ on lagged returns, coupled with GARCH $(1,1)$ residuals. They wanted to select a suitable model for each of the countries. They found that the PAR $(3,1)$ model fitted well in 13 of the 16 emerging models and in 3 of the 5 developed ones. Also, that the return forecasts from the estimated PAR $(3,1)$ model for each of the 21 markets exceeded the forecast from their AR (1) counterparts.

Regarding the Hellenic market there have been a few studies that examine the stock price behavior in the Athens Stock Exchange (ASE). According to Koutmos, Negakis and Theodossiou (1993) the stock prices on the ASE exhibit a stochastic behavior since there exist first and second order dependencies in the return series. They applied the EGARCH-M model, which appeared to explain well the return generating process and the first -and second- order dependencies in the returns' distribution. The authors also found evidence that past returns influenced current returns, both when returns were measured in US dollars and in the local currency.

Niarchos and Alexakis (1998) investigated whether it was possible to predict stock price changes or returns in the ASE under the assumption of a constant equilibrium return. They constructed a sample of 14 pairs of common and preferred stocks based on the most active stocks listed in the ASE, for the period 1991 to 1994. They found that there are factors other than news, which influence the price behavior of stocks. 
Papachristou (1999) found also that market returns in the ASE exhibit first-order serial correlation. Barkoulas, Bawn and Travlos (2000) examined the presence of long memory in stock returns in the ASE. They applied spectral regression methodology (ARFIMA) from 1981 to 1990 and compared its forecasting performance to that of benchmark linear models. The former methodology resulted in greater forecasting accuracy compared to random walk forecasts. Kavussanos and Dockery (2001) examined the efficiency of the Hellenic stock market and found that the ASE is informational inefficient. In other words, past stock prices contain some information about future prices.

\section{METHODOLOGY AND DATA}

A plethora of environmental variables are used in the present study to determine the returns of the Hellenic stock exchange. For the estimation of the returns are preferred the closing prices of the General Index of the Athens Stock Exchange (ASE). The period under examination is about two years, from the $26^{\text {th }}$ of March 2002 till the $29^{\text {th }}$ of June 2004. The total number of observations is 485 daily returns.

In order to examine the relationship between stock returns and environmental variables, the annual stock returns are regressed on the selected variables. The dependent variable is the return of the General Index. A set of nine independent variables is used in the regression equation. These variables are presented in Table 1.

Table 1: Independent Variables, Predictors of Stock Returns

\begin{tabular}{|l|}
\hline$€ / \$$ Exchange rate \\
\hline One lag return of DJ Industrial \\
\hline One lag return of General Index \\
\hline One year rate of Euribor \\
\hline Percent change of the price of gold \\
\hline Closing price of Brent oil in dollars \\
\hline Percent change of three year bond \\
\hline Percent change of ten year bond \\
\hline Trading volume of ASE (in natural logarithms) \\
\hline
\end{tabular}

The source of this study's data is the site of the newspaper "Naftemporiki", www.naftemporiki.gr.What is important here is to examine the sign of each of these variables and its statistical significance. Beyond the regression analysis with the classical ordinary least square (OLS) method, a more contemporary neural network approach, called also neural network regression (NNR) will be employed.

A neural network system (NNS) is a computer program that estimates the physical neural process by which human learning and intuition operate. There are no preexisting rules or structures in the system, but it learns by trial and error. There exists a training procedure which is exposed to correct input/output information sets, repeatedly and the neural network system learns the form of the relationship among the inputs and the outputs. Then there is an examination procedure or step, where the neural system is tested, to investigate how well the data fit the model. Finally, the third step is the testing of the relationships between the inputs and the outputs. [Hawley, Johnson and Raina (1990)]. The neural network system, which is occupied by this study, is called 'Pathfinder'. Neural networks use a set of processing nodes. These processing nodes are interconnected in a network that can then identify patterns in data as it is exposed to the data. Using back propagation a neural network learns through an iterative procedure. The network is repeatedly shown examples of the data to learn and makes adjustments to the weights go that it fits the model better. This process is repeated thousands of times. Three data sets are needed to perform a neural network analysis. The three data sets are the training set, the test set and the validation set. The neural network in order to learn the problem uses the training set. The test set is used during training to monitor the learning performance. The validation set is used after training as a final check to determine how well the model performs.

Neural networks have been proposed as an alternative to traditional statistical forecasting approaches and often perform better than these methods. Their main advantage is that they are model-free universal functions which 
approximate that defect non-linear relationship very well. However, they suffer from the "black box" problem and for over fitting the data. The "black box" is the hidden layer in the process that gives the weights to the variables that is not clear about the functional relationship [Tenti (1996)].

The sample of the present study is comprised by 485 daily returns; hence, 300 observations will be employed for the first set, 70 for the second set and 115 for the third set. Next, the predicted values extracted by the latter set will be compared with the actual values of the daily returns. Next, the mean absolute percent error (MAPE) of the predicted values will be computed using the following formula:

$$
\mathrm{MAPE}=\sum_{i=1}^{n} \frac{\left|\frac{R_{i}-P_{i}}{R_{i}}\right|}{N} * 100, \quad \mathrm{R}_{\mathrm{i}}, \mathrm{N} \neq 0
$$

where $R_{i}$ is the real value, $P_{i}$ is the predicted value and $N$ is the number of observations.

In order to compare the MAPE of a neural network regression to the MAPE of an OLS regression, 370 observations ( 300 from the training set and 70 from the test set) are used to create a multi-regression model. The endogenous variable of this model as mentioned above will be the daily return of the General Index and the exogenous variables will be the nine independent variables that are reported in Table 1. In the next step, the MAPE will be computed in the same way. Last, the MAPE of the OLS regression and the MAPE of the neural network regression will be compared to each other. The lower (higher) value of the MAPE indicates the better (worse) fit of the model.

\section{EMPIRICAL RESULTS}

Table 2 illustrates the values of the OLS coefficients, their $\mathrm{t}$ statistics and the corresponding P-values of the $\mathrm{t}$ statistics.

Table 2 OLS Coefficients

\begin{tabular}{|l|c|c|c|}
\hline \multicolumn{1}{|c|}{ Variables } & Coefficients & t- statistics & P-values \\
\hline Constant & -4.907 & $-1.99 * *$ & 0.048 \\
\hline$€ / \$$ Exchange rate & 1.476 & 0.99 & 0.323 \\
\hline One lag return of DJ Industrial & 0.17309 & $3.97 * * *$ & 0.000 \\
\hline One lag return of General Index & 0.00288 & 0.06 & 0.965 \\
\hline One year rate of Euribor & 0.0404 & 0.18 & 0.859 \\
\hline Percent change of the price of gold & -0.19189 & $-3.05^{* * *}$ & 0.002 \\
\hline Closing price of Brent oil in dollars & -0.06395 & $-2.44 * *$ & 0.015 \\
\hline Percent change of three year bond & -0.2696 & -1.25 & 0.212 \\
\hline Percent change of ten year bond & -0.3879 & $2.64 * * *$ & 0.009 \\
\hline Trading volume of ASE (in natural logarithms) & 0.4406 & $2.83 * * *$ & 0.005 \\
\hline Cor $\left(\mathrm{R}_{\mathrm{i}}, \mathrm{P}_{\mathrm{i}}\right)=0.228$ & $\mathrm{~N}=370$ & $\mathrm{R}^{2}=19.7 \%$ & $\mathrm{~F}=9.8^{* * *}$ \\
\hline
\end{tabular}

First, it is essential to examine the signs of the coefficients estimates. A positive sign of the $€ / \$$ exchange rate implies that a stronger Euro enhances the Hellenic stock market as a strong Euro is an omen that the economy of Europe is healthy. On the other hand, a higher $€ / \$$ exchange rate makes the Euro more expensive relatively to the dollar. As a result, investors that obtain dollars are less likely to invest in European stock exchanges. The coefficient of the sample is positive (1.476) but not statistical significant.

The coefficient of one lag return of the Dow Jones Industrial Index is positive and statistically significant at the $1 \%$ significance level. This implies that previous day's performance of the US stock exchange influences towards the same direction the Hellenic Stock market. Previous day's return of the General Index is not statistically significant 
implying that one day's return does not influence the following day. Bank interest rate measured by the one-year rate of Euribor is not statistically significant as well.

As it was expected, there is an inverse relationship between the percentage change of the price of gold and the performance of the General Index. This connection is statistically significant even at the $1 \%$ level of significance. This contrary direction between the two variables is consistent with the economic theory, since gold is an alternative investment to stocks and the former (latter) is preferred in periods of economic uncertainty (certainty).

Moreover, the closing price of Brent oil in dollars pressures towards the inverse direction the return of the Hellenic stock exchange. This is reasonable as a higher price of oil is a sign or/and a source of economic instability that drives crisis into stock exchanges. Oil price's coefficient is statistically different from zero at the 5\% significant level. The percentage changes of three year and ten-year bonds present negative coefficients but only the latter is statistically significant at the $1 \%$ significance level. Similar to the case of gold, bonds are a safer investment and an alternative option to the more risky stocks. So, it is expected to be a negative relationship between bonds' prices and stock exchanges' returns. The trading volume affects positively the daily return of the General Index. This direct relationship is statistically different from zero at the $1 \%$ level of significance.

The coefficient of correlation between real prices and predicted prices is $\rho=0.228$. This figure implies a positive but weak correlation between the two variables. The coefficient of determination $\mathrm{R}^{2}$ is equal to $19.7 \%$. This value states that the regression model explains the $19.7 \%$ of the regression between the independent variables and the dependent variable. The F statistic is employed to test the null hypothesis that all the coefficients of the regression model are not statistically significant. The value of the $\mathrm{F}$ statistic is 9.8 (corresponding $\mathrm{P}$ value $=0.000$ ). This means that the null hypothesis is rejected for every level of significance.

Furthermore, in addition to the traditional OLS regression approach, a neural network non-parametric approach is employed for the estimation of the General Index' returns. From the total number of 485 observations, 300 are used for the training set, 70 for the test set and 115 for the validation set. Neural networks software supplies corresponding predicted values for the observations of the validation set and the mean absolute percent error (MAPE) of the predicted values. The value of the NNR MAPE may be compared with the value of the OLS MAPE. For the estimation of the OLS MAPE 370 observations (the sum of training set and test set) are employed to estimate the coefficients of variables as described in the previous section. Table 3 illustrates the OLS MAPE and the NNR MAPE.

Table 3 OLS MAPE and NNS MAPE

\begin{tabular}{|c|c|c|c|}
\hline OLS MAPE & OLS MAPE* & NNS MAPE & NNS MAPE* \\
\hline 1666.3 & 1083.2 & 135.6 & 97.2 \\
\hline
\end{tabular}

Note $\rightarrow *$ Excluding $5 \%$ of extreme values

Results in Table 3 show that the NNR offers better-fitted results than the OLS method. The NNR MAPE (135.6) is significantly lower than the OLS MAPE (1666.3). This relationship is still stable even when the 5\% of the extreme values (of absolute percent errors) are excluded from the sample. The coefficient of correlation between predicted and actual prices is 0.345 for the case of NNR. This figure is considerably higher than the coefficient of correlation between predicted and actual values for the case of OLS, which is 0.228 .

As a result, academic researchers and practitioners for the prediction of stock indices forecasting shall prefer NNR. However, the MAPE of NNR even after the exclusion of the 5\% of extreme values remains pretty high implying that there is room for the choice of a more appropriate set of independent variables. This is a task of a future research. 


\section{CONCLUSIONS}

This study tried to compare two approaches, one parametric, OLS regression and one non-parametric, neural networks regression (NNR), in forecasting daily stock returns in the ASE, for the period March 2002 to June 2004. The results indicated that the mean absolute percent error (MAPE) of the predicted values (stock returns) for the NNR was smaller than the equivalent indicator of the OLS approach. Hence, academic researchers and practitioners for the prediction of stock indices forecasting could be advised to prefer NNR. However, the MAPE of NNR even after the exclusion of the $5 \%$ of extreme values remains pretty high implying that might be a more appropriate set of independent variables for predicting stock returns. Furthermore, the NNR approach should be compared to several GARCH models for testing which is the most appropriate one. This, however, is the scope of a future research.

\section{REFERENCES}

1. Akgiray, V. (1989) Conditional Heteroskedasticity in Time Series of Stock Returns: Evidence and Forecasts Journal of Business, 62(1): 55-80.

2. Alexakis, P. and Petrakis, P. (1991) Analyzing Stock Market Behaviour in a Small Capital Market Journal of Banking and Finance, 15: 471-83.

3. Apergis, N. and Eleftheriou, S. (2001) Stock Returns and Volatility: Evidence from the Athens Stock Market Index Journal of Economics and Finance, 25(1): 50-61.

4. Barkoulas, J.T., Baum, C.F. and Travlos, N. (2000) Long Memory in the Greek Stock Market Applied Financial Economics, 10: 177-84.

5. Basci, E., Basci, S., and Muradoglu, G. (2003) Do Extreme Falls Help Forecasting Stock Returns? Evidence from World Markets Presentation at the 2003 Multinational Finance Society Meeting in Montreal, Canada, June 30-July 2, 2003.

6. Basu, S. (1977) The Investment Performance of Common Stocks in Relation to their Price-Earnings Ratios: A Test of the Efficient Market Hypothesis Journal of Finance, 32: 663-82.

7. Campbell, J. (1987) Stock Returns and the Term Structure Journal of Financial Economics, 18: 373-99.

8. Chang, C.W., Ahmad, M.I., and Abdullah, M.Y. (1999) Performance of GARCH Models in Forecasting Stock Market Volatility Journal of Forecasting, 18: 333-43.

9. Chen, N., Roll, R., and Ross, S. (1986) Economies Faces and the Stock Market, Journal of Business, 59: $383-$ 403.

10. Cootner, P.H. (1962) Stock Prices: Random Walk vs. Systemic Changes Industrial Management Review, 3: 24-45.

11. Corhay, A. and Tourani, R., (1994) Statistical Properties of Daily Returns: Evidence from European Stock Markets Journal of Business, Finance and Accounting, 21(2): 271-82.

12. Dunis, C.L. and Jalival, J. (2001) Neural Network Regression and Alternative Forecasting Techniques for Predicting Variables CIBEF-Center for International Banking, Economics and Finance.

13. Diacogiannis, G.P., Tsiritakis, E.D. and Manolas, G.A. (2001) Macroeconomic Factors and Stock Returns in a Changing Economic Framework: The Case of the Athens Stock Exchange Managerial Finance, 27(6): 2341.

14. Fama, E. (1965) The Behavior of Stock Market Prices Journal of Business, 38: 34-105.

15. Fama, E. and French, K. (1988a) Permanent and Temporary Components of Stock Prices Journal of Political Economy, 96: 246-73.

16. Fama, E. and French, K. (1988b) Dividend Yields and Expected Stock Returns Journal of Financial Economics, 22: 3-25.

17. Fama, E. and French, K. (1992) The Cross-section of Expected Stock Returns Journal of Finance, 47: 44765.

18. Fama, E. and Schwert, W. (1977) Asset Returns and Inflation Journal of Financial Economics, 5: 115-46.

19. Franses, P.H. and Homelen, P. (1998) Forecasting Exchange Rates Using Neural Networks Applied Financial Economics, 8: 589-96.

20. Hagerman, R.L. (1978) Notes: More Evidence on the Distribution of Security Returns Journal of Finance, 33: 1213-21. 
21. Harissis, H.F. (1999) Stock Returns and Interest Rates: The Case of Greece European Research Studies, 2(14): $15-32$.

22. Hiemstra, C. and Kramer, C. (1995) Nonlinearity and Endogeneity in Macro-Asset Pricing, International Monetary Fund.

23. Howley, D.D., Johnson, J.D., and Raina D. (1990) Artificial Neural Systems: A New Tool for Financial Decision-Making Financial Analysts Journal, November/December: 63-72.

24. Hsu, D.A., Miller, R.B., and Wichern, D.W. (1974) On the Stable Paretion Behavior of Stock Market Prices Journal of the American Statistical Association, 69: 108-13.

25. Kavussanos, M.G. and Dockery, E. (2001) A Multivariate Test for Stock Market Efficiency: The Case of ASE Applied Financial Economics, 11: 573-9.

26. Kim, D. and Kon, S.J. (1994) Alternative Models for the Conditional Heteroskedasticity of Stock Returns Journal of Business, 67: 563-98.

27. Koutmos, G., Negakis, C., and Theodossiou, P., (1993) Stochastic Behaviour of the Athens Stock Exchange Applied Financial Economics, 3: 119-26.

28. Kryzanowski, L., Galler, M., and Wright, D.W. (1993) Using Artificial Neural Networks to Pick Stocks Financial Analysts Journal, July/August: 21-7.

29. Lakonishok, J., Shleifer, A., and Vishny, R.W. (1994) Contraries Investment, Extrapolation and Risk Journal of Finance, 49: 1541-78.

30. Lau, A., Lau, H., and Wingender, J. (1990) The Distribution of Stock Returns: New Evidence against the Stable Model Journal of Business and Economic Statistics, 8: 217-23.

31. Leung, M.T., Daouk, H., and Chen, A. (2000) Forecasting Stock Indices: A Comparison of Classification and Level Estimation Models International Journal of Forecasting, 16: 173-90.

32. Lo, A.W. and MacKinlay, A.C. (1988) Stock Market Prices do not Follow Random Walks: Evidence from a Simple Specification Test Review of Financial, 1: 41-66.

33. Mertzanis, H.V. (2003) The Efficiency of Microstructure and Return Volatility in the Greek Security Market $2^{\text {nd }}$ Hellenic Finance and Accounting Association Meeting.

34. Nelson, M., Hill, T., Remus, W., and O'Connor, M. (1999) Time Series Forecasting Using Neural Networks: Should the Data be Deseasonalized First? Journal of Forecasting, 18: 359-67.

35. Niarchos, N.A. and Alexakis, C.A. (1998) Stock Market Prices, 'Causality' and Efficiency: Evidence from the Athens Stock Exchange Applied Financial Economics, 8: 167-74.

36. Osborne, M.F.M. (1959) Brownian Motion in the Stock Market Operations Research, 7: 145-43.

37. Osborne, M.F.M. (1959) Periodic Structure in the Brownian Motion of stock Prices Operations Research, 10: 345-79.

38. Panas, E. (1990) The Behavior of Athens Stock Prices Applied Economics, 22: 1715-27.

39. Papachristou, G. (1999) Stochastic Behavior of the Athens Stock Exchange: A Case of Institutional Nonsynchronous Trading Applied Financial Economics, 9: 239-50.

40. Peters, E.E. (1989) Fractal Structure in Capital Markets Financial Analyst Journal, July/August.

41. Tenti, P. (1996) Forecasting Foreign Exchange Rates Using Recurrent Neural Networks Applied Artificial Intelligence, 10: 567-81. 


\section{NOTES}

